\title{
Metamodernism: the Phenomenon of Memory as Part of an Architectural Concept
}

\author{
Elina Danilova ${ }^{1, *}$ Daria Bakshutova ${ }^{1, a}$ \\ ${ }^{1}$ Faculty of Architecture, Samara State Technical University, Samara, Russia \\ ${ }^{a}$ Email: bakshutova94@gmail.com \\ *Corresponding author. Email: red_avangard@mail.ru
}

\begin{abstract}
Metamodernism defines the structure of the feeling of the contemporary epoch characterized by an appeal to all past cultures in order to find the sources of the new. The phenomenon of memory has become again relevant and in demand in architecture discipline. The desire for constant innovation in modernism and postmodern irony were replaced by a serious attitude to any surviving fragments and a desire to materialize the layers of different epochs. The article describes three levels of work with memory in architecture: retrospection, reminiscence, and commemoration. Various objects are considered, architectural and planning concepts are analyzed, therefore architecture is able to visualize genealogy, evoke memories, capture momentous events and artifacts. Such analysis allows drawing conclusions and getting an idea of the spirit of our time and the values of society expressed in the latest architecture.
\end{abstract}

Keywords: Collective memory in architecture, Architectural genealogy, The traces of time.

\section{INTRODUCTION}

The last quarter of the century is a time of profound changes in the world. Globalization has remolded the economic and social space. Economic inequality has increased. Wars, financial crises, the emergence of a mass precariat, environmental disasters, pandemics, and instability, which manifests itself in all areas of human life are the main features of the contemporary landscape. The triumph of consumerism is substituted by the understanding of the resources finiteness, celebrating the boundless world is replaced by anti-globalist moods and the search for national identity. All the processes are developed against the mass use of computer and information technologies in the daily lives of most of the world's population.

Such large-scale and radical changes distinguish our epoch from the postmodern period and indicate the need for a new definition of the cultural logic of our epoch. There are different versions of such definitions. Some of them are related to technological characteristics. Thus, A.Kirby calls our time digimodernism [1], and R.Samuels names it "automodernism" referring to the concepts of "autonomy" and "automatism"[2]. G.Lipovetsky offers a definition of "hypermodern" while exploring the creative nature of contemporary capitalism [3]. N.Bourriaud believes that the time has come for altermodernism [4]. These definitions reflect individual aspects. The most general widely used term is "metamodernism" introduced by T.Vermeulen and R. van den Akker in 2010 [5].

The prefix meta, derived from the Greek metaxix, indicates the state of "between", which is a characteristic of contemporary reality. There are constant fluctuations between the extremes: global and local, cultural and technological, rational and irrational. Metamodernism rejects neither the strategies or tactics of postmodernism, nor modernism, nor the classics. On the contrary, metamodernism includes any practices and any ideas ever existing. However, while postmodernism has addressed to the past with irony, creating parodies of canonical objects and concepts, metamodernism carefully collects any remnants and fragments in order to reinterpret them and assemble a new whole based on them. 
For metamodernism, sincerity and seriousness are important. Everything that has ever been created by humanity in culture and art can be used for a metamodern project. Conscious consumption, secondary use became the new normal. Ecoconsciousness also affects culture. But there is another important trend developed over the last quarter of a century that influenced the formation of the metamodernism paradigm and its structure of feeling most. Such trend is the cultivation of the phenomenon of memory in contemporary culture. In 2002 P.Nora published an important text declaring a world celebration of memory [6].

Since the late 1990s, a memorial boom has been primarily associated with political changes - the destruction of the bipolar world and the restoration of the historical memory of the Eastern bloc countries [7]. The globalization processes leading to intensive migration processes, the destruction of local cultures and nations and territories identity loss were the second important factor. Contrary trends developed in response to these processes: restoration of the destroyed, return of the forgotten, construction of genealogy. The number of museums is increasing at a tremendous rate. Everything possible to archive is archived. Thanks to computer technology, this process has become accessible to everyone. Any organization and any person can have their own archives. Each cycle of urbanization leads, on the one hand, to the destruction of the traditional way of life, and on the other hand, to attempts to preserve any traces existing before. Metamodernism demonstrates its inherent constant fluctuation between memory and oblivion, between perpetuation and erasure, between extremes determining the attitude to the past.

There is a massive request for identity and authenticity that can only be satisfied if the genealogy of the object exists. But unlike history that remains a strict scientific discipline memory provides an opportunity to express your emotions and your attitude. Memory is individual, whimsical, touches the feelings - all these determine the uniqueness opposed to mass character and globality. The flip side of the coin is that, thanks to uniqueness, it is possible to preserve memory without getting lost in the general flow of liquid reality as defined by Z.Bauman [8]. Memory creates steadiness, the most desired quality nowadays. The classical architecture traditionally performed the memory function. Architectural metamodernism restores this function with all the seriousness. At the same time, the phenomenon of memory, as a cognitive process, is the result of contemporary media culture filled with images of memories, nostalgia.
The three waves of the memorial boom and the corresponding memory studies over the past century have been a response to wars, industrialization and urbanization. Each cycle of destruction created a desire to remember and restore. So the appeal for order after the radical avantgarde became a reason to recall the classical values in architecture. The demolition of historical buildings in the late modernism period determined an alternative trend of recreating historical centers and preserving heritage. But metamodernism extends its passion for the materialization of memory to any traces of the past, regardless of whether they are preserved in reality or in memories. It is important to start the processes of remembering and recollection, and this leads to the fact that the phenomenon of memory becomes part of the architectural concept.

There are several levels of expression of the memory phenomenon in contemporary architecture. The article considers the three most common of them: retrospection, reminiscence, and commemoration. Various examples demonstrate how the architecture of memories is formed providing the identity and genealogy of the urban environment and the authenticity of the material environment. The role of such architecture is to awaken emotions, to form the structure of the feeling of the metamodernism epoch, where there is no contradiction between the old and the new, but a constant fluctuation between extremes, as a condition of being.

\section{RETROSPECTION}

Retrospection as an artistic technique is often used in literature and cinema. Moments of the past are involved in the current reality, allowing to fully reveal the plan, give a clue and show the genesis of what is going on now. Mass retrospection in architecture has started with the adaptation of industrial heritage in post-industrial cities. Harbors, hangars, factory buildings promised not only an alternative spatial experience, but also the material basis for the genealogy of the new development. The reconstruction of such objects made it possible to create freer interpretations impossible when working with architectural heritage. The extremes involved in the composition like old and new fragments are emphasised by the material and form.

The most famous object of that kind is the building of the Elbphilharmonie (Herzog \& de Meuron, 2017). The basis of the building is a packhouse dated 1963 and erected on the site of a historic warehouse in 1875 , above which there is a giant glass crystal with plenty of associations. The 
object grows out of this environment naturally and its genealogy enhances its value and uniqueness ("Figure 1"). The Elbphilharmonie has become an example for many subsequent reconstructions around the world.
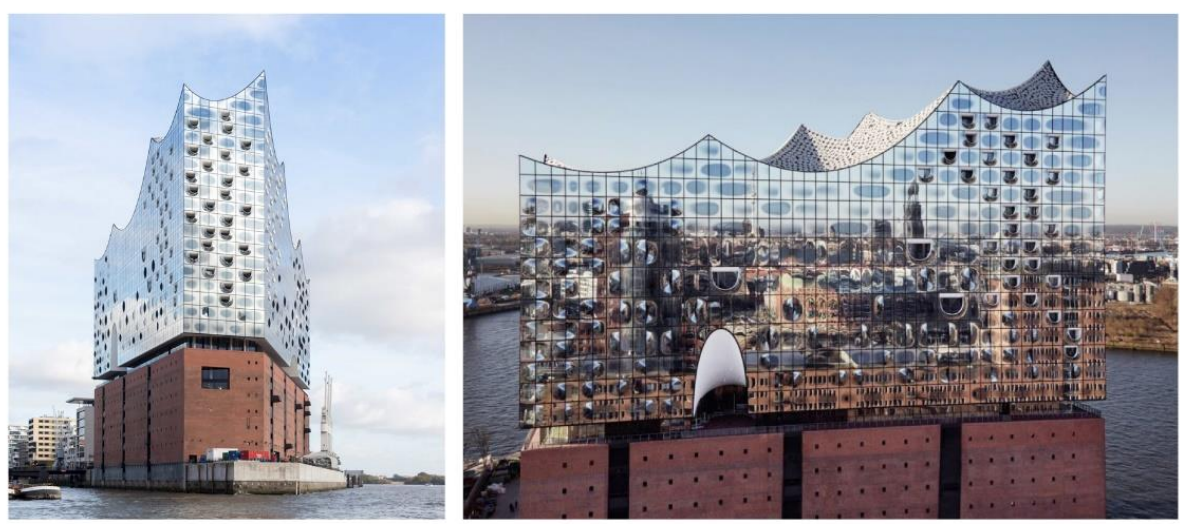

Figure 1 Elbphilharmonie, Herzog \& de Meuron, 2017.

At a time when the implementation of any forms in architecture becomes possible thanks to computer technology, an alternative to blobs and flows is architectural retrospection, caused by the desire to take root in the existing reality and emphasize the "handicraft" quality of the object. The desire to preserve any remnants of industrial buildings stems not only from economic relations, but from a passionate desire to capture the memory of the place and imprint it into the fabric of the piece of work. In the newly completed Fenix object in Rotterdam (Mei architects and planners, 2019), the utilitarian building needs to be preserved and incorporated into the body of the object just to show the time overlays.

The retrospective in industrial objects was continued in other typologies. Flashbacks began to appear wherever possible. Everywhere you can find inclusions and sprinklings of remnants, as necessary evidence of the past constantly serving as a reminder that everything has its origins. One of the most striking examples of the use of memory traces in an open space project is the High line Park in New York (Diller Scofidio + Renfro, 2009-2019). Such a memory trace in the project is the former railway overpass, where the green boulevard is now located, as well as the rails preserved and recreated on it ("Figure 2"). The example of the park illustrates the spread of the urban movement to preserve the identity of neighborhoods and historic sites. In the architecture of metamodernism, public spaces are now considered as the most important carriers of such identity and collective memory: everyday practices, rituals and the nature of places.

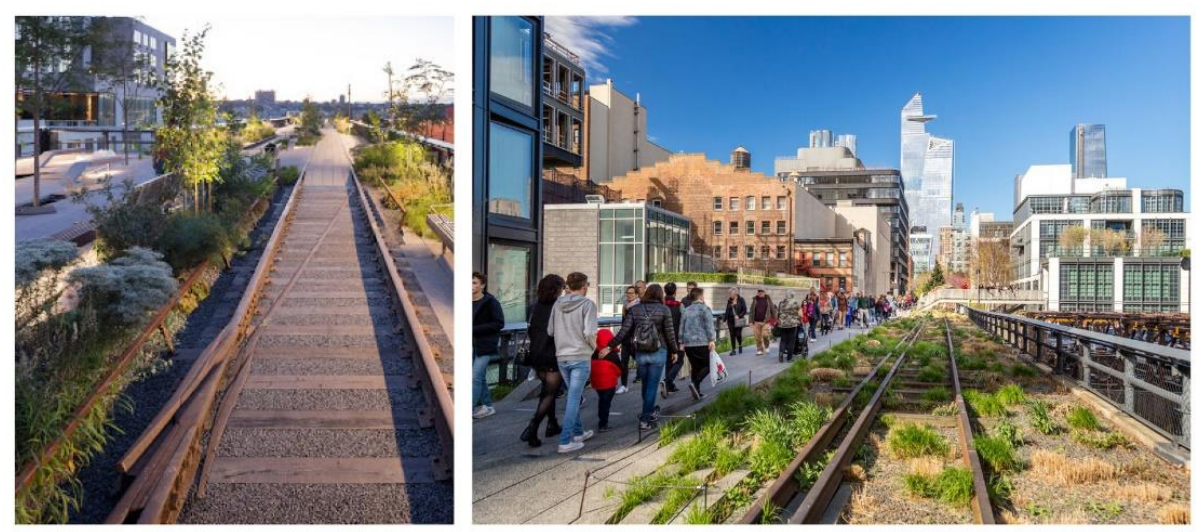

Figure 2 High line Park in New York, Diller Scofidio + Renfro, 2009-2019.

In addition to preservation, it is possible to "reinvent" identity aimed at correcting historical mistakes and losses caused by the global processes of industrialization and urbanization. Among the newest examples is Tainan Spring Park (MVRDV, 2020) where a public square with an urban pool and green spaces was created on the site of a shopping center no longer of relevance in the era of online shopping. The 
square is surrounded by galleries consisting of fragments of shopping center structures and the underground parking level has been transformed into a pool with steam fountains. The park aims to restore the memory of this place as part of the Tainan harbor with the sea fishing as main trade before industrialization.

The development of memories and historical traumas can also be associated with projects of adapting ruins. Retrospection is clearly evident in the projects of including historical fragments into the structure of new buildings. The Kolumba Museum, designed by Peter Zumthor (Cologne, 2007), is built on the ruins of the Gothic church of St. Kolumba destroyed during the Second World War. The new structure "grows" out of the ancient foundation. The exhibition halls hover over historical fragments on tall white columns. Such work with the historical heritage helps to overcome the loss of the old image of the city and the way of life.

Objects of retrospection can resist the "forgetting" of the historical city by maintaining and developing the local culture and economy. In the project of the "Clos Pachem" winery located in the oldest part of the village in the municipality of Tarragona (Harquitectes, 2020), the old wall becomes the foundation for the entire building. A stone wall of irregular shape serves as a border with neighboring areas. Its geometry, the combination of stones, ceramic screeds and plaster remnants became the starting point for the project. The main hall of the winery with the equipment "steps aside" from the wall and a passage with multi-level green roofs, paved platforms, stairs and cross-walks, reflecting the spirit of the historical city in a contemporary, hightech object is formed in the created space.

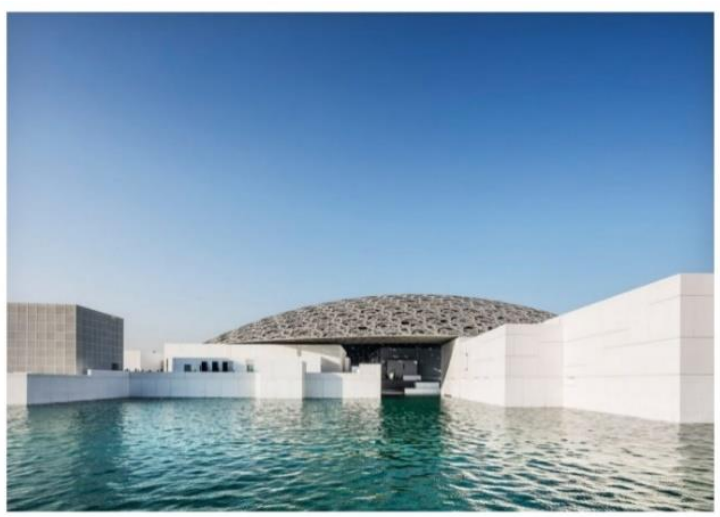

Figure 3 Louvre Abu Dhabi, Jean Nouvel, 2017.

In the project of the museum of the Portuguese artist Casa das Histórias Paula Rego (Eduardo Souto

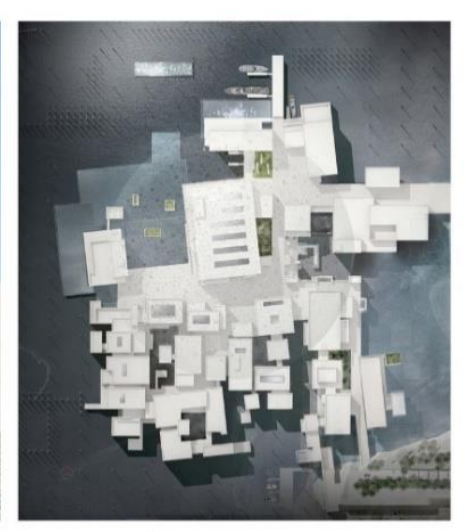

\section{REMINISCENCE}

A person loses his identity when he loses his memories. Memories have influence on selfidentification and provide continuity between the past, present and future. In the art of architecture, memories turn into allusions, echoes, and reminiscences that create multiple connotations and define the complexity of the architectural organism. Crafts, technologies and forms are disappearing. The space is changing. But the architecture is able to preserve the memory of them. Memories can form a goal and indicate the meaning of an architectural object. Through materialized memories, the environment gains continuity and depth.

Reminiscences allow preserving the memory of the historical environment currently undergoing destruction and gentrification. In the project of the Philharmonic Hall in Szczecin (2014), the Barozzi Veiga bureau uses a form that refers to the memory of the historical city. A large volume seems to consist of a whole block of narrow and vertical burghers' houses. The pitched roofs remind of the context and Gothic verticals of the city.

Reminiscences can also become part of a project when it is necessary not to just maintain an identity, but to form it and materialize it in a certain area. The Louvre Abu Dhabi (Jean Nouvel, 2017) shows echoes of the traditional Eastern dome and the structure of the museum under it is similar to the historical buildings of the old Arab medina ("Figure 3"). Paradoxically, the opportunity to create such a cultural artifact appeared in this place exactly due to globalization, since it is necessary to maintain the uniqueness of the local culture. de Moura, 2009) in the city of Cascais inspiration for the pyramidal shape of the main volumes are the 
reminiscences of the history of Portuguese architecture: Royal Sintra National Palace smokestacks, utter roofs of the houses by the architect Raul Lino, stove in the kitchen of Alcobaça Monastery and other images. The reminiscences in the object refracted by the creative preferences and techniques of the author-architect serve the purpose of preserving the local cultural memory.

Another example demonstrates the use of memories for preserving local history and unique

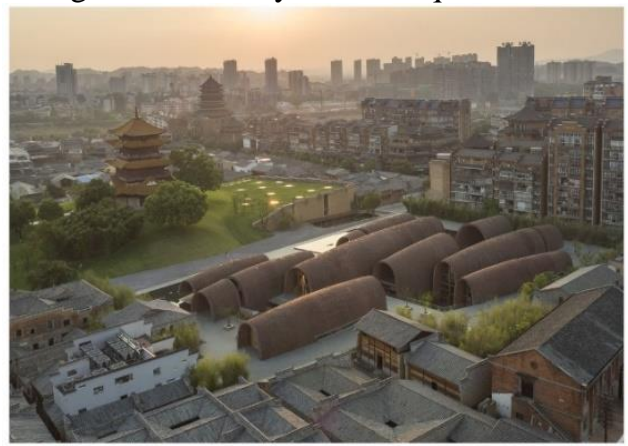

culture in the urban space characteristic of contemporary China. The architectural solution of the Imperial Kiln Museum in Jingdezhen (Studio Zhu-Pei, 2020) uses a historical prototype of ancient kilns. The building is a series of brick vaults stretched in parallel to each other, similar in shape to porcelain kilns. Historically, the stoves were dismantled after several years of operation, and the bricks were reused - they were utilized in the project of the new museum in combination with the new ones ("Figure 4").

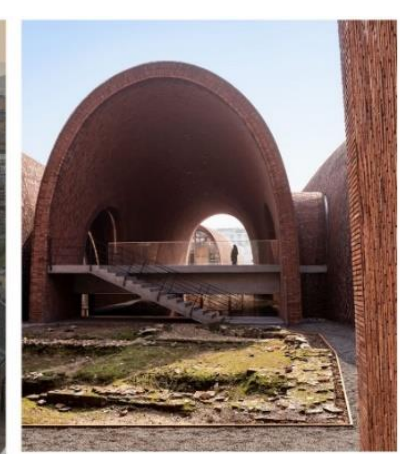

Figure 4 Imperial Kiln Museum in Jingdezhen, Studio Zhu-Pei, 2020.

\section{COMMEMORATION}

The purpose of any commemorative practices is to fix special events in the collective memory and update them in the present. Architecture can carry out commemoration not only due to the typology of memorial objects. The site itself can become an official memorial to what has ever defined the uniqueness and value of a populated area. The destruction of small towns, historical areas, rural settlements and landscapes during the rapid urbanization of recent decades evokes special feelings of nostalgia for the outgoing environment and the desire to preserve its image in the collective memory.

Such memory of a lost village and an old way of life is shown by the example of a public space in the
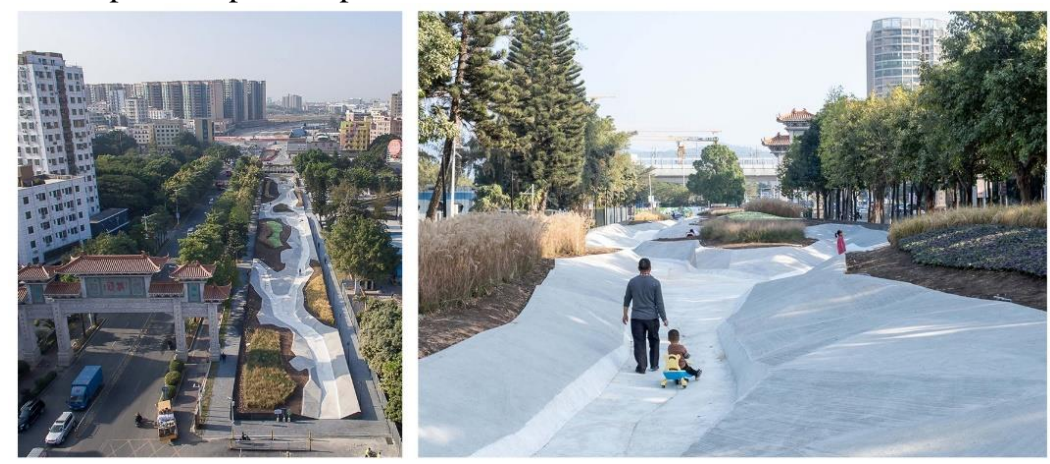

Figure 5 Park in the Qiaotou, Shenzhen, NODE Architecture \& Urbanism, 2019. 
The Fuyang Cultural Complex (Wang Shu, 2016) also seeks to capture the memory of the receding landscape of rural China. The exhibition gallery is dedicated to Huang Gongwang, a landscape artist who painted "Dwelling in the Fuchun Mountains" (1350), one of the most significant works of Chinese painting, in the immediate vicinity of the new building. The complex has a complicated silhouette due to the wavy ceiling, referring to traditional Chinese roofs. The ceiling serves as an artificial landscape, resembling the mountains view in the background. The roof surface is assembled from different materials: recycled bricks and tiles, natural stone, textured concrete. On top of this complex landscape, paths and bridges are laid, referring to the image of the Chinese garden.

Another example recreates one of the layers of history to preserve the memory of the city. The project of public space around the antique Temple of Diana in Merida (José María Sánchez García, 2011) restores the historical memory of the place by returning the key function of forum for the Roman

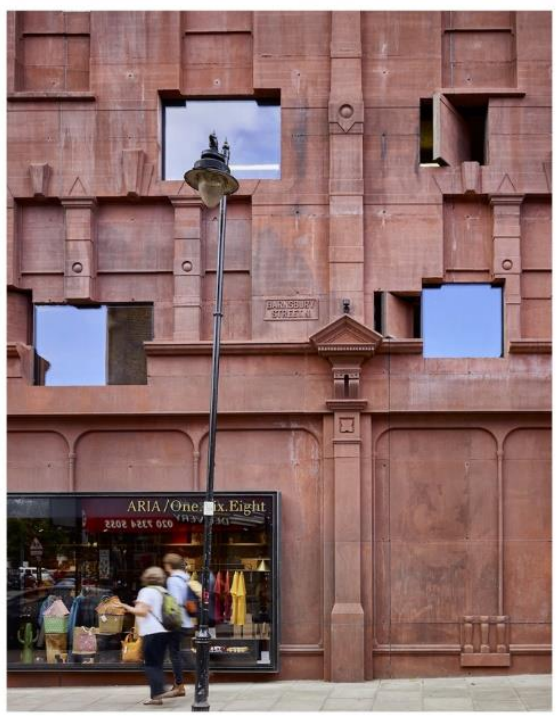

city. The project aims to recreate the central space of the citywide forum, with the articulation of "emptiness" becoming the main element. Along the perimeter of the square there is a gallery duplicating the ancient peristyles. All the surfaces of this structure are made like the marble ancient buildings of the same material - light-coloured concrete, artificial stone, rewording the natural one.

The project of an apartment building at 168 Upper Street, London, designed by Amin Taha + Groupwork (2017) restores the memory of the place where the original building was destroyed during the bombing of London. The remaining void became significant for the residents of the district as a memory and a small square in a dense housing. The project involves recreating the Victorian facade of tinted concrete with a layer of new structure appearing on the outer surface of the form. The historical architectural form is interpreted like a single shell structurally not depending on the internal content, but being a layer of history and memory ("Figure 6").

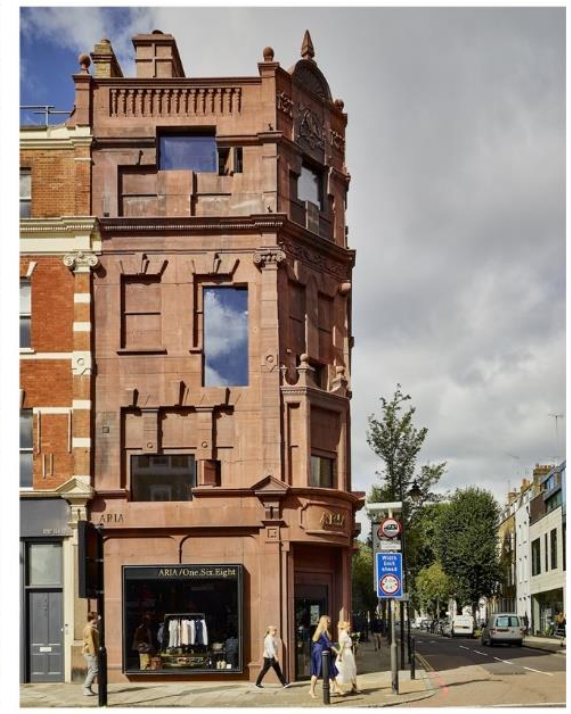

Figure 6168 Upper Street, London, by Amin Taha + Groupwork, 2017.

In the BIG project of Danish National Maritime Museum (2013), the emptiness of the old dry dock is a memory carrier, both of this place and of the entire maritime history of Denmark. The museum is located underground around the space of the former dock. The void is punctuated by bridges-passageways that provide a connection inside the museum, as well as associating it to Kronborg Castle. The project demonstrates the preservation of the memory of the traditional culture of navigation, the maritime achievements of Denmark, and also captures the memory of a place turned from a shipbuilding enterprise into a cultural center in the post-industrial period.

Commemoration helps to revive decaying places, updating them for the collective memory. The Place of Remembrance project of cultural center in Lima (Barclay \& Crousse, 2015) "restores" the memory of the landscape structure lost during the construction of the highway and at the same time seeks to "heal the wounds" in society - the exhibition is dedicated to the goal of reconciliation of the Peruvian people after the conflict started in 1980 by the terrorist movement, having killed more than 70,000 people. With such 
tough mission, the project addresses to the landscape as something permanent and unifying.

\section{CONCLUSION}

The basis of the retrospect can be any historical elements: buildings and their fragments, individual constructions, details, materials left after demolition. If available, they are included into a new object. Historical fragments serve the purpose of forming a sense of authenticity, faithfulness, truthfulness confirming the uniqueness and special character of the place. The inclusion of historical fragments into contemporary objects assures that history was really carried out in this place. At the same time, old fragments evoke empathy for past events, epochs and people. Objects that combine the old and the new allow us to move more confidently into the future, because they show that historical fragments continue existing and developing even after they have been subjected to loss of meaning, destruction or desolation.

The basis of reminiscences is the historical, cultural, natural context. The context can be either local or refer to fairly large cultures and regions. Since objects with reminiscences can be erected at any place not necessarily possessing historical material traces, they can serve to maintain the cultural memory of large communities of people. The role of the author in the selection and combination of allusions is important, since it is him who selects what needs to be remembered. At the same time, a memory is not an exact reproduction, but rather an iteration, inspiration, or recognition of some properties in another object. Subtle echoes create complex connotations, appealing to the different emotions of spectators and users.

The basis of commemoration is the heritage of the community, its collective memory - uniqueness, peculiarity, outstanding achievements, traditions, identity of a particular place and community. Commemoration in architectural objects is carried out both at the level of national and local heritage: an object can have a memorial value for a block, district, city or the whole country. Modern objects aimed at commemoration tend to use several layers of memory and express it at different levels of architecture. Examples of commemoration associated with specific places and communities are more likely to try to better understand the present than to create an image for future descendants, as did the examples of past epochs.
Multiple use of memory in projects can make it routine and lead to the opposite result of erasure and oblivion. However, the architecture of metamodernism, aimed at achieving sustainability, seeks to turn the phenomenon of memory to a specific place and community, which is the key to diversity and uniqueness in contemporary architecture and establishes a link between the past, present and future.

\section{AUTHORS' CONTRIBUTIONS}

Both authors contributed equally to the study conception and design, drafted the work and revised it critically for important intellectual content, approved the final manuscript.

\section{REFERENCES}

[1] G. Lipovetsky, Hypermodern Times, Politypress, London, 2005.

[2] A. Kirby, Digimodernism. How New Technologies Dismantle the Postmodern and Reconfigure Our Culture, Continuum, New York, London, 2009.

[3] N. Bourriaud, Altermodern, Tate Publ., London, 2009.

[4] R. Samuels, Auto-Modernity after Postmodernism: Autonomy and Automation in Culture, Technology, and Education, in: $\mathrm{T}$. McPherson (Ed), Digital Youth, Innovation, and the Unexpected, MIT Press, Cambridge, 2007, pp. 219-240.

[5] T. Vermeulen, R. van den Akker, Notes on metamodernism, Journal of Aesthetics and Culture 2 (2010) 1-14. DOI: https://doi.org/10.3402/jac.v2i0.5677

[6] P. Nora, The Reasons for the Current Upsurge in Memory. URL: https://www.iwm.at/transitonline/the-reasons-for-the-current-upsurge-inmemory/ (accessed: 25.02.2021).

[7] G. Feindt, F. Krawatzek, D. Mehler, F. Pestel, R.Trimçev, Entangled memory: Toward a third wave in memory studies, History and Theory 53 (1) (2014) 24-44. DOI: https://doi.org/10.1111/hith.10693

[8] Z. Bauman, Liquid Modernity, Polity Press, Cambridge, 2000. 